Discussion Papers of the

Max Planck Institute for

Research on Collective Goods

2020/15

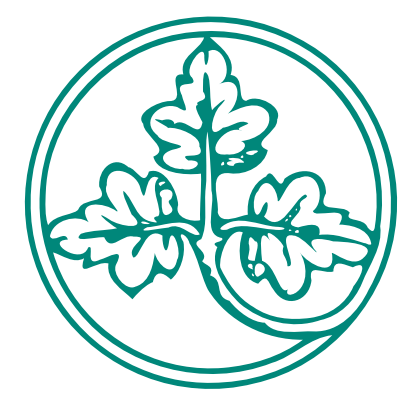

Property Taxes and Dynamic Inefficiency: A Correction of a "Correction"

Martin F. Hellwig 


\title{
Property Taxes and Dynamic Inefficiency: A Correction of a "Correction"
}

\author{
Martin F. Hellwig
}

June 2020 


\title{
Property Taxes and Dynamic Inefficiency: A Correction of a "Correction"
}

\author{
Martin F. Hellwig \\ Max Planck Institute for Research on Collective Goods \\ Kurt-Schumacher-Str. 10 \\ D-53113 Bonn, Germany \\ hellwig@coll.mpg.de
}

June 25, 2020

\begin{abstract}
According to Homburg's (2014) comment on Kim and Lee (1997), an ad-valorem property tax on land cannot cause dynamic inefficiency of equilibrium allocations in an overlapping-generations model unless the tax is "confiscatory", i.e., equal to or greater than land rents. With such a tax, Homburg claims, land would be intrinsically worthless and the market for land would be closed. The latter claims are invalid because, as a store of value, land can be traded at a positive price even if the net rate of return on land is negative.

JEL Classification: D9, E62, H21

Key Words: Property taxes, dynamic inefficiency, overaccumulation of capital, land.
\end{abstract}

\section{Introduction}

This note takes issue with the objection that Homburg (2014) raised against the criticism of Kim and Lee (1997) against Homburg (1991). The debate concerns the scope for dynamic inefficiency of equilibrium allocations in overlappinggenerations economies. ${ }^{1}$

Following Samuelson (1958), ${ }^{2}$ Diamond (1965) had provided instances of such equilibria in which a very high demand for a store of value by each generation supported holdings of real capital at a level where the net rate of return on capital was less than the real growth rate and a Pareto improvement could

\footnotetext{
${ }^{1}$ After writing a first draft of this piece, I learnt from editorial correspondence related to Hellwig (2020) that Stefan Homburg has also written, but so far not made public, a correction to his 2014 piece in Economics Letters. This correction, however, has the same flaw as the original piece and is internally inconsistent. Details can be obtained from the author.

${ }^{2}$ The argument actually goes back to Allais (1947, Appendix 2), who also introduced the objection of Homburg (1991).
} 
be obtained by reducing each young generation's real investment and transferring the resources saved to provide for consumption of the older generation. Homburg (1991) had put forward the proposition that, in an economy with private markets for land, i.e., a non-produced, long-lived asset, the phenomenon of dynamic inefficiency cannot arise because the net own rate of return on land necessarily exceeds the growth rate of the economy.

According to Kim and Lee (1997), Homburg's (1991) claim is not generally valid in the presence of a property tax on land. Homburg (2014) argues that, for the conclusion of Kim and Lee to be true, the property tax must be confiscatory. A confiscatory tax, however, "would close this market, making land as intrinsically worthless as Samuelson's (1958) bubbly money."

In this argument, the word "confiscatory" refers to a tax that equals or exceeds the income derived from land. It does not refer to a tax that equals the sum of the income and the proceeds from selling the land. With this meaning of the word "confiscatory", the claim that a confiscatory property tax would close the market for land is incorrect.

A confiscatory property tax in the specified sense of the term may cause the net rate of return on land to be smaller than the growth rate of the economy, but that does not necessarily make land worthless. If the need for a store of value is sufficiently large and there are no better stores of value around, people may be willing to hold land even though the net rate of return is smaller than the rate of growth. In the absence of uncertainty, since rates of return on different assets must be the same, they would also be willing to invest in real capital at a level where the net rate of return is smaller than the rate of growth.

This phenomenon can arise even if the income effects of the taxes are neutralized by using the revenues from these taxes to fund lump-sum subsidies to the consumption of the older generation (as in Kim and Lee (1997)). If the tax revenues were used to provide lump-sum subsidies to the younger generation, they would add to the need for a store of value.

\section{Framework}

Consider a model with an infinite sequence of periods $t=1,2, \ldots$ In each period $t$, there is a single produced good, which can serve for consumption and for investment. An investment $k$ in period $t$ generates an output $f(k)$ in period $t+1$, where $f(\cdot)$ is a continuously differentiable, strictly increasing, and strictly concave production function, with $f^{\prime}(0)=\infty$. In the process of production, capital is fully used up. There also is land, a non-produced asset, a unit of which provides $a$ units of the produced good in each period.

In each period, a new generation of $N$ people is born. A person born in period $t$ lives for two periods and is interested in the consumption good in periods $t$ and $t+1$. The person's preferences are given by the utility function $u\left(c_{1}^{t}\right)+$ $u\left(c_{2}^{t}\right)$, where both $c_{1}^{t}$ is consumption in the first period and $c_{2}^{t}$ is consumption in the second period of the person's life. The function $u(\cdot)$ is continuously differentiable, strictly increasing, and strictly concave, with $u^{\prime}(0)=\infty$. 
A person born in period $t$ has initial endowments $E>0$ of the produced good in period $t$ and zero of the produced good in period $t+1$ and of land. In period 1, there is also an old generation of size $N$. Each member of this generation has endowments $k^{0}, L^{0}>0$ of capital and land and gets utility $u\left(c_{2}^{0}\right)$ from consuming $c_{2}^{0}$.

In each period $t$, there is a market in which land can be traded against the produced good of that period at the price $q_{t}$. The person who has held the land from period $t-1$ to period $t$ gets the revenue $q_{t} L^{t-1}$ but must pay a property tax equal to $\tau q_{t-1} L^{t-1}$ per unit of land. The proceeds of the tax are used for a lump-sum payment $S^{t}$ to the members of the old generation in period $t$.

Given the land prices $q_{t}, q_{t+1}$ in periods $t$ and $t+1$ and the tax rate $\tau$ and the lump-sum subsidy $S^{t}$, a person born in period $t$ chooses a consumption plan $\left(c_{1}^{t}, c_{2}^{t}\right)$ and a portfolio $\left(k^{t}, L^{t}\right)$ so as to maximize the objective

$$
u\left(c_{1}^{t}\right)+u\left(c_{2}^{t}\right)
$$

subject to the constraints

$$
c_{1}^{t}=E-k^{t}-q_{t} L^{t}
$$

and

$$
c_{2}^{t}=f\left(k^{t}\right)+\left(a+q_{t+1}-\tau q_{t}\right) L^{t}+S^{t} .
$$

An equilibrium is given by a land price sequence $\left\{q_{t}\right\}_{t=1}^{\infty}$ and an allocation $\left\{c_{2}^{t-1}, c_{1}^{t}, k^{t}, L^{t}\right\}_{t=1}^{\infty}$ such that the following conditions hold:

1. $c_{2}^{0}=f\left(k^{0}\right)+a L^{0}+q_{1} L^{0}-\tau q_{0} L^{0}+S^{0}$;

2. for $t=1,2, \ldots$, the quadruple $\left(c_{1}^{t}, c_{2}^{t}, k^{t}, L^{t}\right)$ maximizes the utility (1) under the constraints (2) and (3);

3. for $t=1,2, \ldots$,

$$
N\left(c_{2}^{t-1}+c_{1}^{t}+k^{t}\right)=N\left(E+f\left(k^{t-1}\right)+a L^{t-1}\right)
$$

and

$$
N L^{t}=N L^{t-1}
$$

4. finally, for $T=0,1, \ldots$,

$$
S^{t}=\tau q_{t} L^{t}
$$

I will focus on stationary equilibria. An equilibrium is said to be stationary if the land price $q_{t}$ is constant over time.

Proposition 1 For any $\tau>0$, there exists a unique stationary equilibrium. The equilibrium is characterized by a pair $(\delta(\tau), q(\tau))$, which is the unique solution to the equations

$$
\delta=\frac{a}{q}+1-\tau,
$$




$$
q L^{0}=E-k^{*}(\delta)-c_{1}^{*}(\delta) .
$$

Given $(\delta(\tau), q(\tau))$, the equilbrium satisfies

$$
\left(q_{t}, c_{1}^{t}, c_{2}^{t}, k^{t}, L^{t}, S^{t}\right)=\left(q, c_{1}^{*}(\delta(\tau)), c_{2}^{*}(\delta(\tau)), k^{*}(\delta(\tau)), L^{0}, \tau q L^{0}\right)
$$

where, for any $\delta>0,\left(c_{1}^{*}(\delta), c_{2}^{*}(\delta), k^{*}(\delta)\right)$ is the unique solution to the equations

$$
\frac{u^{\prime}\left(c_{1}\right)}{u^{\prime}\left(c_{2}\right)}=f^{\prime}(k)=\delta
$$

and

$$
c_{1}+c_{2}=E+f(k)-k+a L^{0}
$$

Proof. By (5) and (6), trivially, any equilibrium satisfies $L^{t}=L^{0}$ and $S^{t}=$ $\tau q L^{0}$ for all $t \geq 1$. The first-order conditions for the maximization of (1) subject to (2) and (3) imply

$$
\frac{\lambda_{t}}{\mu_{t}}=\frac{u^{\prime}\left(c_{1}^{t}\right)}{u^{\prime}\left(c_{2}^{t}\right)}=f^{\prime}\left(k^{t}\right)=\frac{a}{q_{t}}+\frac{q_{t+1}}{q_{t}}-\tau,
$$

where $\lambda_{t}$ and $\mu_{t}$ are the Lagrange multipliers of the constraints (2) and (3). If $q_{t}$ is the same for all $t$, it follows that $\frac{\lambda_{t}}{\mu_{t}}$ is the same for all $t$. Define $\delta(\tau)$ as the common value of $\frac{\lambda_{t}}{\mu_{t}}$ for $t \geq 1$. Then (12) implies that, for all $t, c_{1}^{t}, c_{2}^{t}, k^{t}$ must satisfy (10) with $\delta=\delta(\tau)$. From (2), (3), and the equations $L^{t}=L^{0}$ and $S^{t}=\tau q L^{0}$, one also finds that $c_{1}^{t}, c_{2}^{t}, k^{t}$ must satisfy (11) for all $t$. Under the given assumptions on $u$ and $f$, for any $\delta>0$, equations (10) and (11) have a unique solution $\left(c_{1}^{*}(\delta), c_{2}^{*}(\delta), k^{*}(\delta)\right)$.

Equations (2) and (7) imply that the pair $(\delta(\tau), q(\tau))$ must satisfy $(7)$ and (8). To see that this pair of equations has at most one solution, use (7) to substitute for $\delta$ in (8). This yields the equation

$$
q L^{0}=E-k^{*}\left(\frac{a}{q}+1-\tau\right)-c_{1}^{*}\left(\frac{a}{q}+1-\tau\right) .
$$

The left-hand side of this equation is obviously increasing in $q$. Further, $k^{*}(\cdot)$ and $c_{1}^{*}(\cdot)$ are decreasing functions and so is the function $q \rightarrow \frac{a}{q}+1-\tau$. The righthand side of (13) is therefore decreasing in $q$. Thus (13) has no more than one solution. To see that a solution exists, it suffices to observe that, for $q=E / L^{0}$, the left-hand side exceeds the right-hand side, and for $q \rightarrow 0, k^{*}\left(\frac{a}{q}+1-\tau\right)$ and $c_{1}^{*}\left(\frac{a}{q}+1-\tau\right)$ converge to zero, so the right-hand side converges to $E>$ $\lim q L^{0}=0$.

Given the solution $(\delta, q)$ to equations $(7)$ and (8), one easily verifies that the allocation and subsidy sequence that are obtained from (9) - (11) satisfy all conditions for a stationary equilibrium. 


\section{The Impact of Taxes}

I next consider the dependence of stationary equilibria on the tax rate $\tau$. Notice that $\tau$ enters equations (9) - (8) only through equation (7), the first-order condition for the demand for land. The solution to (10) and (11) does not depend on $\tau$ directly, but only indirectly, through $\delta(\tau)$, though not through $q(\tau)$.

Remark 2 The functions $\tau \rightarrow q(\tau)$ and $\tau \rightarrow \delta(\tau)$ are decreasing.

Proof. Because $k^{*}(\cdot)$ and $c_{1}^{*}(\cdot)$ are decreasing functions, the right-hand side of (13) is decreasing in $\tau$. Because the difference between the left-hand side and the right-hand side is increasing in $q$, it follows that $q(\tau)$ is decreasing in $\tau$. By inspection of (8), it follows that $\delta(\tau)$ is also decreasing in $\tau$.

Proposition 3 Assume that

$$
E>k^{*}(1)+f\left(k^{*}(1)\right)+a L^{0},
$$

and let

$$
\tau^{*}=\frac{2 a L^{0}}{E-\left(k^{*}(1)+f\left(k^{*}(1)\right)+a L^{0}\right)}
$$

and

$$
q^{*}=\frac{E-\left(k^{*}(1)+f\left(k^{*}(1)\right)+a L^{0}\right)}{2 L^{0}} .
$$

Any stationary equilibrium satisfies

$$
\delta(\tau) \gtreqless 1 \text { and } q(\tau) \gtreqless q^{*} \text { as } \tau \lesseqgtr \tau^{*}
$$

Proof. By Remark 2, it suffices to show that, for $E$ satisfying (14) we have $\delta\left(\tau^{*}\right)=1$ and $q\left(\tau^{*}\right)=q^{*}$, where $\tau^{*}, q^{*}$ are given by (15) and (16). For $\tau^{*}, q^{*}$ given by (15), (16), we obviously have $\frac{a}{q^{*}}=\tau^{*}$, so (7) implies $\delta=1$. For $\delta=1$, (10) and (11) and the strict concavity of $u(\cdot)$ imply

$$
c_{1}^{*}(1)=c_{2}^{*}(1)=\frac{1}{2}\left(E+f\left(k^{*}(1)\right)-k^{*}(1)+a L^{0}\right),
$$

so the right-hand side of (8) takes the form

$E-k^{*}(1)-\frac{1}{2}\left(E+f\left(k^{*}(1)\right)-k^{*}(1)+a L^{0}\right)=\frac{1}{2}\left(E-\frac{1}{2}\left(k^{*}(1)+f\left(k^{*}(1)+a L^{0}\right)\right.\right.$,

implying that (8) holds if and only if $q=q^{*}$.

The variable $\delta(\tau)$ indicates the stationary-equilibrium value of the implicit relative price of the produced good in periods $t$ and $t+1$. The assumption underlying Proposition 3, inequality (14), makes the first-period endowment $E$ so large that, if $\delta(\tau)=1$, the demand for a store of value exceeds $k^{*}(1)$, so the 
equilibrium price of land must be strictly positive even though, at the tax rate $\tau^{*}$, land has a zero net rate of return.

If the property tax rate $\tau$ is greater than $\tau^{*}$, the equilibrium value of $\delta(\tau)$ is less than one, and we have

$$
c_{1}^{t}=c_{1}^{*}(\delta(\tau))>c_{1}^{*}(1)=c_{2}^{*}(1)>c_{2}^{*}(\delta(\tau))=c_{2}^{t},
$$

as well as

$$
f^{\prime}\left(k^{t}\right)=f^{\prime}\left(k^{*}(\delta(\tau))\right)=\delta(\tau)<1=f^{\prime}\left(k^{*}(1)\right)
$$

and

$$
\frac{a}{q(\tau)}+1-\tau=\delta(\tau)<1
$$

As indicated by (20), it follows that, for $\tau>\tau^{*}$, in stationary equilibrium, the net rate of return on both real capital and land is negative and therefore smaller than the growth rate of the economy (which is zero because of the stationarity of the population). By standard arguments, it follows that a Pareto improvement is available by having each person consume a bit less in the first period and a bit more in the second period of their life. ${ }^{3}$

The claim that "confiscatory" taxation, in the sense of the term used by Homburg (2014), would close the market for land is false. The tax may make land "intrinsically worthless" in the sense that it fails to earn a positive net return, but that does not mean that land has no value in the market. Homburg's claim to the contrary is the more surprising as he himself draws an analogy to "Samuelson's (1958) bubbly money". Surely he must be aware that an entire branch of monetary theory is devoted to studying how the existence of markets for "Samuelson's (1958) bubble money" may enable the economy to meet its needs for a store of value. ${ }^{4}$

\section{Discussion}

How are we to interpret the dynamic inefficiency for $\tau>\tau^{*}$ ? It seems inappropriate to see this inefficiency on a par with the dynamic inefficiency discussed in Diamond (1965). The inefficiency in Diamond (1965) involves a failure of the first welfare theorem, i.e., a case where an equilibrium allocation under laissez-faire fails to be Pareto-efficient. The dynamically inefficient equilibria in Proposition 3 do not involve laissez-faire. The inefficiency is due to taxation. Inefficiencies from taxation are common fare in public economic theory. Ordinarily we think of such inefficiencies in terms of quantity reductions when supplies or demands are elastic. However, as was pointed out by Feldstein (1977), taxes

\footnotetext{
${ }^{3}$ For details, see Hellwig (2020). For $\tau=\tau^{*}$, such a Pareto improvement is not available; the equilibrium allocation is dynamically efficient.

${ }^{4}$ For a synthesis of this literature, see Grandmont (1983), cited in Homburg (1992). For a critique, see Hellwig (1993).
} 
that affect rates of return on assets can have distortionary effects even if the assets in question are inelastically supplied. ${ }^{5}$

The difference between the dynamic-inefficiency findings in Diamond (1965) and in Kim and Lee (1997) or in Proposition 3 above becomes clear if one considers the implied policy prescriptions. In Diamond (1965), a finding of dynamic ineffiency gives rise to a recommendation to use public debt as a substitute for real capital as a store of value. ${ }^{6}$ Public debt might also serve the purpose here, but a reduction in the tax rate on land would more directly address the cause of the inefficiency.

The logic of Kim and Lee (1997) and of Proposition 3 can however be used to establish the possibility of dynamic inefficiency in the sense of a violation of the first welfare theorem if transactions involving land are costly. In Hellwig (2020), I use a model similar to the one studied here to show that with an ad-valorem transaction cost $\tau$ on the sale of a piece of land, no matter how small $\tau$ may be, if the need for a store of value is sufficiently large (if $E$ is sufficiently large), any stationary equilibrium allocation is dynamically inefficient and can be improved upon by fiscal policy, e.g., a pay-as-you-go system for retirement provision.

\section{References}

[1] Allais, M. (1947), Économie et Intérêt, Imprimerie Nationale, Paris.

[2] Diamond, P.A. (1965), National Debt in a Neoclassical Growth Model, American Economic Review 55, 1126 - 1150.

[3] Feldstein, M. (1977), The Surprising Incidence of a Tax on Pure Rent: A New Answer to an Old Question, Journal of Political Economy 85, 349 360.

[4] Grandmont, J.-M. (1983), Money and Value, Econometric Society Monograph 5, Cambridge University Press, Cambridge, UK.

[5] Hellwig, M.F. (1993), The Challenge of Monetary Theory, European Economic Review 37, 215 - 242.

[6] Hellwig, M.F. (2020), Dynamic Inefficiency and Fiscal Interventions in an Economy with Land and Transaction Costs, Discussion Paper 2020/07, Max Planck Institute for Research on Collective Goods, Bonn.

\footnotetext{
${ }^{5}$ Feldstein (1977) considered a tax on pure rent. Contrary to a claim in Kim and Lee (1997, fn. 6), and in line with Homburg (2014), the incidence of such a tax is similar to that of a property tax. Dynamic efficiency is obtained if the tax rate $t$ is no greater than one, i.e. if after-tax rent $(1-t) a$ is nonnegative; dynamic inefficiency is obtained if $t>1$. The equilibrium land price satisfies an analogue of equation (20), $q=a \frac{1-t}{\hat{\delta}-1}$, which is positive because $t>1$ implies $\hat{\delta}<1$.

${ }^{6}$ See also Blanchard (2019).
} 
[7] Homburg, S. (1991), Interest and Growth in an Economy with Land, Canadian Journal of Economics 24, 450 - 459.

[8] Homburg, S. (1992), Efficient Economic Growth, Springer-Verlag, Berlin.

[9] Homburg, S. (2014), Property Taxes and Dynamic Efficiency: A Correction, Economics Letters 123, 327 - 328.

[10] Kim, K.-S., and J. Lee (1997), Reexamination of Dynamic Efficiency with Taxation on Land, Economics Letters 57, 169 - 175..

[11] Samuelson, P.A. (1958), An Exact Consumption-Loan Model of Interest with or without the Social Contrivance of Money, Journal of Political Economy $66,467-482$. 